\title{
PID Based on a Single Artificial Neural Network Algorithm for Intelligent Sensors
}

\author{
J. Rivera-Mejía*, A.G. Léon-Rubio ${ }^{2}$, E. Arzabala-Contreras ${ }^{3}$ \\ 1,2,3 División de Estudios de Posgrado e Investigación del Instituto Tecnológico de Chihuahua. Av. Tecnológico No. \\ 2909, Chihuahua, Chihuahua. México, 31310; \\ Tel. +52 (614) 413 7474; Fax. +52 (614) 413 5187; \\ *jrivera@itchihuahua.edu.mx
}

\begin{abstract}
Today control is required in any field or application. Nowadays, classic control is the most used, but it is well-known that users need to know the system's characteristics to reach optimal control. This paper is focused on designing a proportional integral derivative control, based on a single artificial neural network with the aim to improve its performance and its use with minimal control knowledge from the end user. The proposed control was assessed with simulated and practical physical systems of first and second order. In order to increase the confidence of the intelligent sensor control, the evaluation was made using the classical test of control response of a step as input. The proposed control was implemented on an intelligent sensor with a small microcontroller. Also, the performance was compared between the proposed control and a commercial control. Here, an intelligent sensor is presented with control capability for a wide variety of physical systems. The experiments performed demonstrated the capability of the proposed control, which can be easily used and save time at the initial control set up.
\end{abstract}

Keywords: control, intelligent sensors, intelligent control, artificial neural network.

\section{RESUMEN}

Hoy en día el control es requerido en cualquier área o aplicación. En nuestros días, el control clásico es el más utilizado, pero para alcanzar un control óptimo, éste requiere que los usuarios conozcan las características del sistema a controlar. Este documento está enfocado en el diseño de un control proporcional derivativo basado en una sola red neuronal, con desempeño del control mejorado y que su uso requiera de mínimos conocimientos de control. El control propuesto fue evaluado utilizando software para simulación, sistemas físicos de primer orden y segundo orden reales. Con el fin de incrementar la confianza del control propuesto, se evaluó el desempeño utilizando técnicas de control clásico, la respuesta a una entrada escalón. El control propuesto se implementó en un sensor inteligente que utiliza un microcontrolador. El desempeño del control propuesto se comparó con un control comercial. También, aquí se presenta un sensor inteligente con capacidad de control que puede mantener en control una amplia variedad de sistemas físicos. Los experimentos realizados demuestran la capacidad del control propuesto, el cual puede ser utilizado fácilmente y ahorrar tiempo en el trabajo inicial de sintonizar el control.

\section{Introduction}

Nowadays, technology is candidate to be called smart [1]. In particular, the term "smart sensors" originated from different opinions [2-4]. The Institute of Electrical and Electronics Engineers (IEEE) organization has made the effort to create the standard IEEE 1451 in order to uniform this concept [1]. An interesting point of view about the concept of smart sensor is that about its functionality listed as: compensation, processing, communication, integration, validation and data function as it was summarized in [5]. If the sensor includes a larger number of functionalities, it will be more intelligent [6]. Due to the importance and broadness of these functionalities, they are considered individually. This paper is focused on the processing functionalities of intelligent sensors, processing task that involves signal conditioning, signal conversion, logic functions, data reduction that is used to enhance the received signal, and decision making in conjunction with other signal types from other sensors [6]. Cases of processing functionality, as example, can be reviewed elsewhere [7-12]. In order that an intelligent sensor can be capable of taking decisions, is necessary a special control algorithm with features of easy implantation like low computational requirements, 
adaptive, simple, reliable, and so on. In the literature about control, there is diverse work related with proportional integral derivative (PID) control because most of the industrial controllers are still using PID algorithms. To facilitate PID control, it makes extensive use of intelligent tools that have been developed to assist engineers to achieve the best overall PID control [13]. Some control problems can be solved using proportional integral (PI) algorithms [14-15]. Now is required to do control across networks and different examples can be found in literature as the PI algorithm with adaptations to work on transmission control protocol (TCP) [15], the effective mobile sensor control method [16] or the wireless control system closed over wireless local area network [17]. We can see how control requirements are not limited to industrial applications; now they can be found in important environmental care applications [18].

Intelligent control using artificial neural networks (ANN), fuzzy logic or both have been used as alternative to solve all problems instead of classic control. For example an integrated intelligent control based on fuzzy logic for controlling the calorific value and pressure of the mixed gas is presented in [19] or the fuzzy logic control based on quality of the service management [20]. A lot of works for control based on ANN can be found in literature, such as the control based on ANN for a mobile inverted pendulum [21], or the uses of ANN to tune the parameters of a PID controller [22-24]. Another control based on ANN applied to induction motor control is presented in [25]. Efforts to make adaptive control to control linear and nonlinear systems are shown in $[26,27]$ or the proposal of [28] using ANN to build a predictive control. As well known, the PID control with fixed gain, after a long time of system operation has the disadvantage of not working properly due to system parameters variations. In order to solve this problem a combination between ANN and PID controller [22$24,29]$ has been proposed.

Nevertheless, PID controller is simple and combined with ANN most of its disadvantages have been solved such as all the cases that can be found in literature of recent controllers based on the classical PID control as the adaptive PID control using a single neuron [30-43] all those works are focused on solving specific control problems for a particular plant, in some cases is not clear the activation function that was used $[30,32,35,36$, $37,39,40,41,43]$, beside, is not clear which was the criteria to choose the initial parameters because in all the examples [30-43] the initial parameters are based on simulation. Therefore, it is necessary a special analysis and study over those algorithms in order to clarify its capabilities and to make the appropriate evaluation to determinate if the adaptive PID control using a single neuron can be a solution to be used on intelligent sensors.

In this paper is presented the design of an adaptive PID based on a single artificial neural network algorithm (PID-SANNA). A methodology to evaluate its performance was based on classical control criteria, the evaluation of the response to a step as input of reference using first and second order plants was done. The computational requirements were calculated, the practical implementation was done on an intelligent sensor with a small eight bits microcontroller. The final probe was done over a $\mathrm{RC}$ network, a current direct motor and an oven as physical systems. Finally, the topology of an intelligent sensor network with the capability of monitoring and controlling a variable with minimal overall setup from a non-expert in control knowledge.

\section{Design of a pid based on a single neuron algorithm for intelligent sensors}

As mentioned above, five functionalities for intelligent sensors have been defined: compensation, processing, communication, integration, validation and data function. This work is focused on the processing functionality, described as the ability to provide the most relevant information in an efficient representation to the communication interface. This processing task involves signal conditioning, signal conversion, logic functions, data reduction that is used to enhance the received signal, and, decision making in conjunction with other signal types from other sensors [5]. Now, the basic idea is to design a control algorithm that is simple, reliable and has low computational requirements that can be used in intelligent sensors with minimal set up requirements, so that users with low knowledge in control theory can use it.

If considering the basic loop control with unitary feedback shown in Figure 1, using $Z$-transform 


\section{PID Based on a Single Artificial Neural Network Algorithm for Intelligent Sensors, J. Rivera-Mejía et al. / 262-282}

the traditional PID digital algorithm $G_{D}(z)$, can be described as [44]:

$$
U(z)=\left[K_{P}+\frac{K_{I}}{\left(1-z^{-1}\right)}+K_{D}\left(1-z^{-1}\right)\right] E(z)
$$

Where $E(z)$ is the error signal calculated as $E(z)=R(z)-Y(z)$, the signal reference $R(z)$ minus system condition $Y(z) . K_{P}$ is the proportional gain, $K_{I}$ is the integral gain and $K_{D}$ is the derivative gain. These gains are related as follows: $K_{P}=K-\frac{K T}{2 T_{i}}=K-\frac{K_{I}}{2}, K_{I}=\frac{K T}{T_{i}}$ and
$K_{D}=\frac{K T_{d}}{T}$, where $K$ is the gain, $T$ is the sample time, $T_{i}$ is the integration time and $T_{d}$ is the derivative time.

Applying the inverse $Z$-transform to Equation (1) the PID algorithm in discrete time $u(k T)$ or the sequence $u(k)$ can be obtained by (2).

where $e(k)$ is the error between the set point $r(k)$ and the physical system state $y(k)$, computed as:

$$
e(k)=r(k)-y(k)
$$

and $k=0,1,2, \ldots$

$$
u(k T)=u(k T-1)+K_{P}[e(k T)-e(k T-1)]+K_{I} e(k T)+K_{D}[e(k T)-2 e(k-1)+e(k T-2)]
$$

or

$$
u(k)=u(k-1)+K_{P}[e(k)-e(k T-1)]+K_{I} e(k)+K_{D}[e(k)-2 e(k-1)+e(k-2)]
$$

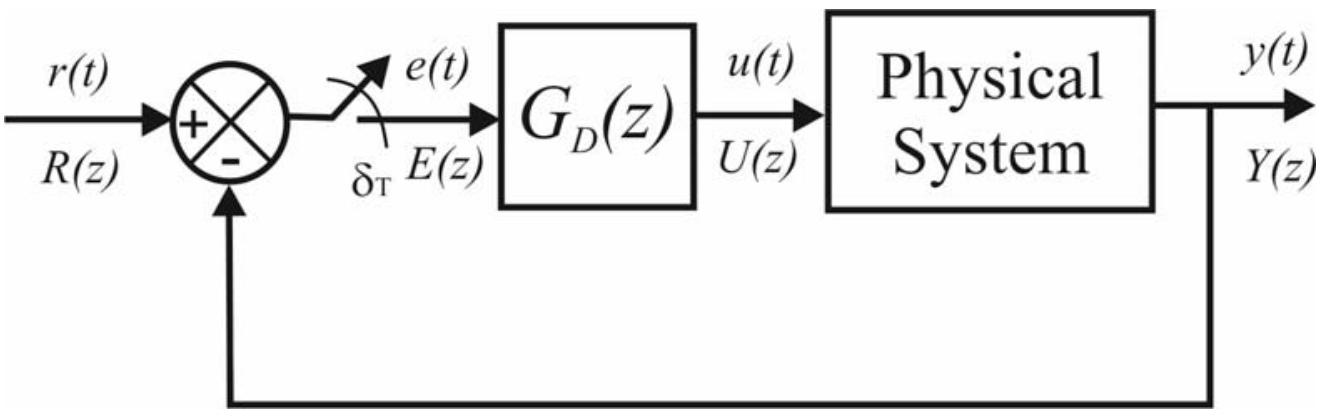

Figure 1. Loop of classic control. 
As can be seen, the algorithm described in quation (2) is simple. However, as is well known, the main problem is tuning the $K_{P}, K_{I}$ and $K_{D}$ according to the plant features in order to get optimal control. Besides, the plant features across the time can vary and then it is necessary to readjust these parameters. The user's knowledge about control theory is required most of the time. Then the PID algorithm is not the solution for the requirements mentioned before.

Using ANN for auto tuning $K_{P}, K_{I}$ and $K_{D}$ gains is a good solution for solving the PID problems. A PID based on one single ANN algorithm [30-43] is analyzed and its design will be improved. Its topology is shown in Figure 2.

Equation (2) can be rewritten as:

$$
u(k)=u(k-1)+K_{P} x_{1}(k)+K_{I} x_{2}(k)+K_{D} x_{3}(k)
$$

where $x_{1}(k), x_{2}(k)$ and $x_{3}(k)$, are:

$$
\begin{aligned}
& x_{1}(k)=e(k)-e(k T-1) \\
& x_{2}(k)=e(k) \\
& x_{3}(k)=e(k)-2 e(k-1)+e(k-2)
\end{aligned}
$$

These variables are multiplied by the weights $w_{i}(k)$ and the results are the neuron input to get the summation function $I$ as:

$$
I=\sum_{i=1}^{3} x_{i}(k) w_{i}(k)
$$

Using the Hebbian rule, weights values are incremented by the factor $\Delta w_{i}$ to train the neuron:

$$
\Delta w_{i}=\eta_{i} x_{i}(k) e(k) u(k)
$$

For $i=1,2,3$ where $\eta$ is the learning factor.

The new value $w(k)$ is:

$$
w_{i}^{\prime}(k)=w_{i}(k-1)+\Delta w_{i}(k)
$$

In order to limit the values of $w_{i}(k)$ to finite values, the new weights are computed using:

$$
w_{i}(k)=\frac{w_{1}^{\prime}(k)}{\left\|\sum_{i=1}^{3} w_{i}^{\prime}(k)\right\|}
$$

The symbol || || denotes Euclidian norm.

For the neuron output $\Phi(I)$, a nonlinear activation function was selected; the hyperbolic tangent to get:

$$
\Phi(I)=A_{\max } \frac{1-e^{-I}}{1+e^{-I}}
$$

The original maximum value of this function is from -1 to +1 as value of $A_{\max }$. This maximum value can be escalated to any value.

Now the output $u(k)$ of the new proportional integral derivative, based on single artificial neural network algorithm (PID-SANNA), can be expressed by the following equation:

$$
u(k)=u(k-1)+\Phi(I)
$$

for $k=1,2,3, \ldots$.

Then the PID-SANNA can be summarized as follows:

a) Initial values $\eta_{1}, \eta_{2}, \eta_{3}, w_{1}, w_{2}, w_{3}$ and $r$ are required.

b) Using Equation 3, the error $e(k)$ is computed.

c) With Equation 5 , the values of $x_{1}(k), x_{2}(k)$ and $x_{3}(k)$, are obtained.

d) The output algorithm $u(k)$ is computed by Equation (10) plus $u(k-1)$.

e) Using Equations (7) to (9), new values for $w_{1}, w_{2}$ and $w_{3}$ are obtained.

f) The new control effort $u(k)$ in computing using Equation (11), is applied to the system and then goes to step b). 


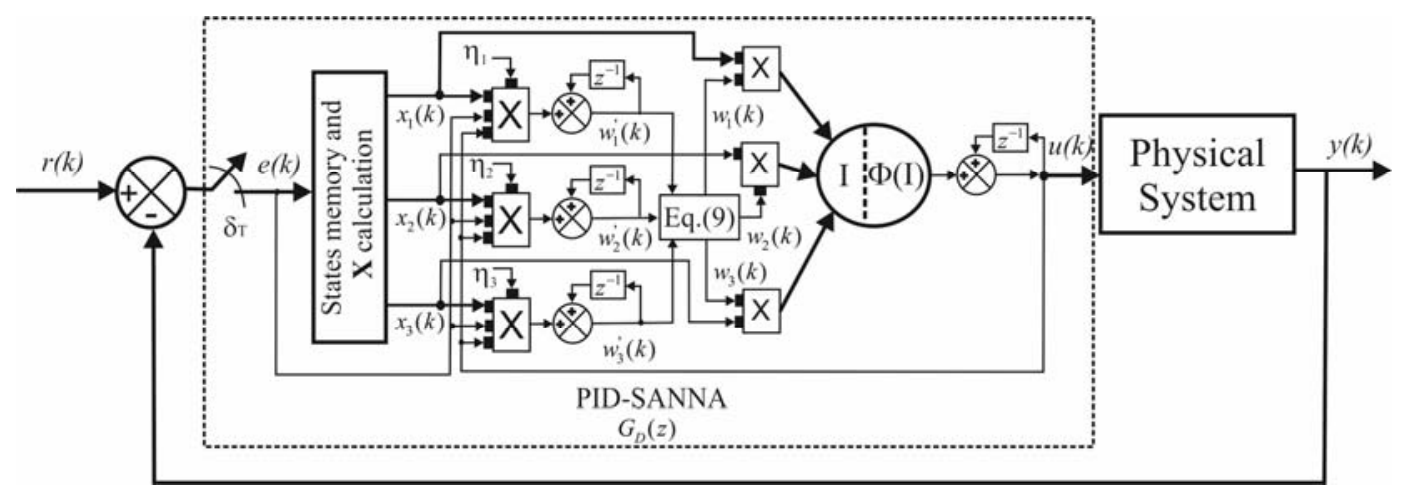

Figure 2. PID control based on a single ANN.

2.1 Initial parameters selection and evaluation of PID-SANNA

Using physical systems models of first and second order simulation software, the initial parameters were obtained and evaluation of the PID-SANNA was done.

First, systems of first order were used and changes to its delaying time $\tau$ in values of $0.0047 \mathrm{~s}, 0.047 \mathrm{~s}, 0.1551 \mathrm{~s}, 0.2209 \mathrm{~s}$ and $0.47 \mathrm{~s}$ where made. After a few simulations, the initial values for the algorithm were selected as: $w_{1}(0)=1, w_{2}(0)=-0.5, w_{3}(0)=-0.5, \eta_{1}=0.1$, $\eta_{1}=0.01$ and $\eta_{1}=0.001$. As is desired that the $\Phi(I)$ reach values between -5 to 5 the value of $A_{\max }$ in Equation (8) was defined in 5. In order to evaluate the response to the classical control test, the reference input $r(k)$ or set point of a step of 100 units was selected. The response to step of the control system of Figure 2 is shown in Figure 3.

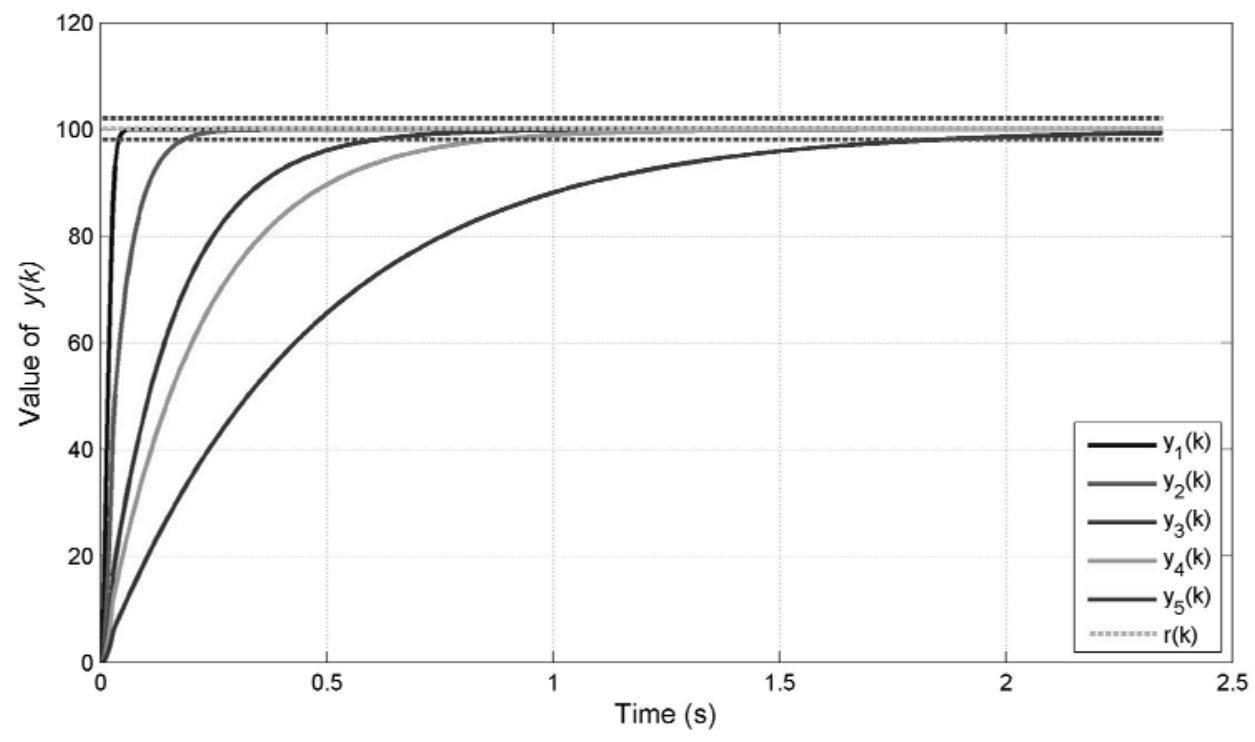

Figure 3. Response to the step of PID-SANNA with first-order plants. 
Second, a typical second order model was used as physical system or plant. The transfer function equation in s-transform that describes the system is:

$$
H(s)=\frac{w_{n}^{2}}{s^{2}+2 \zeta w_{n} s+w_{n}^{2}}
$$

Where $w_{n}$ is the system natural frequency and $\zeta$ is the damping ratio. Then, plants with this features were simulated using $w_{n}=1$ and the damping ratio varied in the range from 0.1 to $1.0,0.1<\zeta<1.0$, in increments of 0.1 . Figure 4 shows the simulated plants.
After a few simulations, the initial values of the algorithm where selected as: $A_{\max }=5, w_{1}(0)=100$, $w_{2}(0)=-50, w_{3}(0)=-20, \eta_{1}=1, \eta_{1}=0.5$ and $\eta_{1}=0.5$. In order to evaluate the response to the classical control test, the reference input $r(k)$ or set point of a step of 100 units was selected.

The response to the step of the PID-SANNA control system, Figure 2, did not work properly with second order plants, which $\zeta<0.4$ and works properly with plants where $0.4 \leq \zeta \leq 1.0$ as shown in Figure 5.

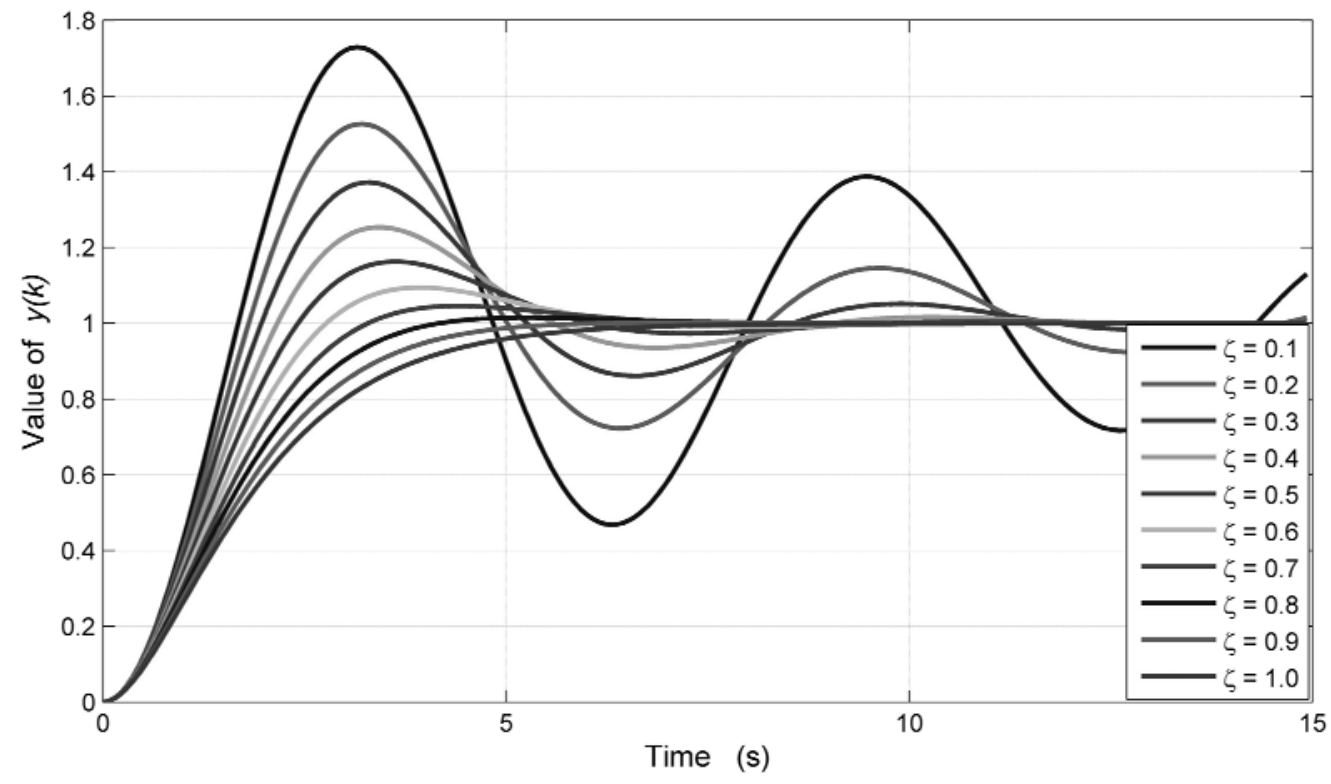

Figure 4. Second-order physical systems with $0.1<\zeta<1.0$. 


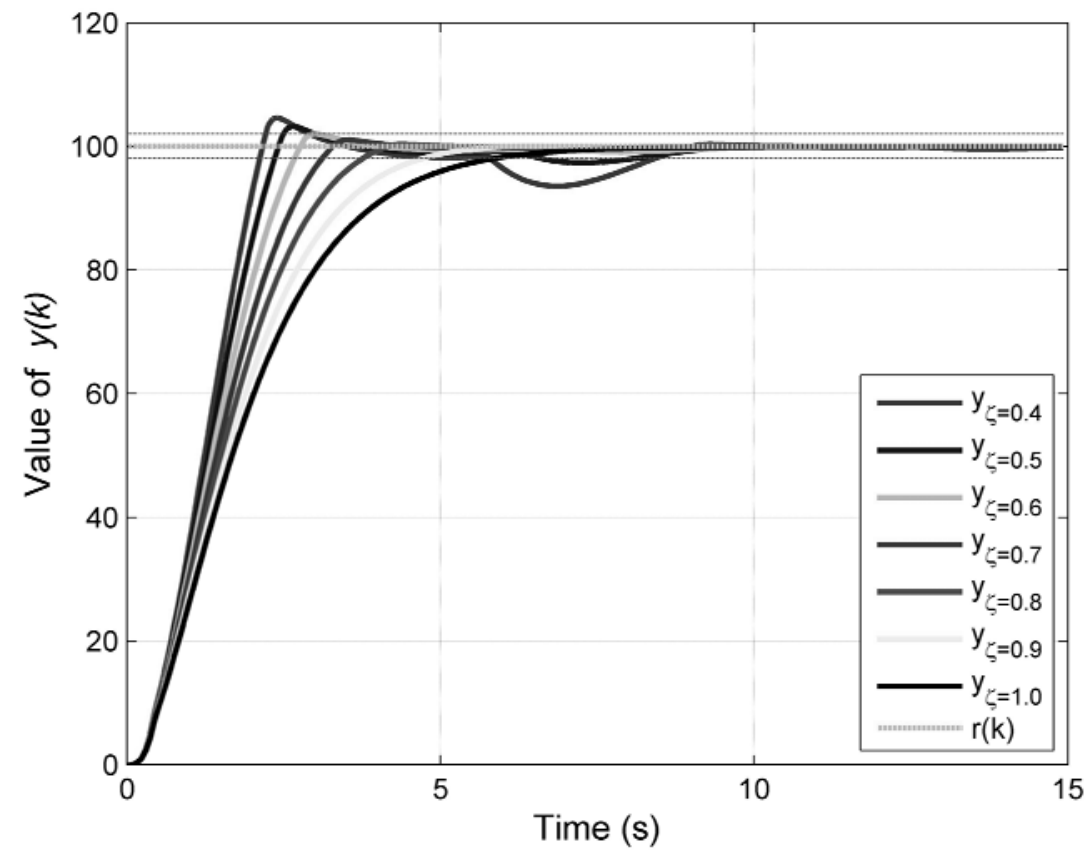

Figure 5. Response to step of PID-SANNA with second-order plants.

An important parameter to evaluate the step response of a control system is the overshoot that is presented in the system output, in Figure 6, the overshoot value for second-order plants with
$0.4 \leq \zeta \leq 1.0$, is shown. As can be observed, it is less than $5 \%$ and for a lot of practical cases, this value is acceptable.

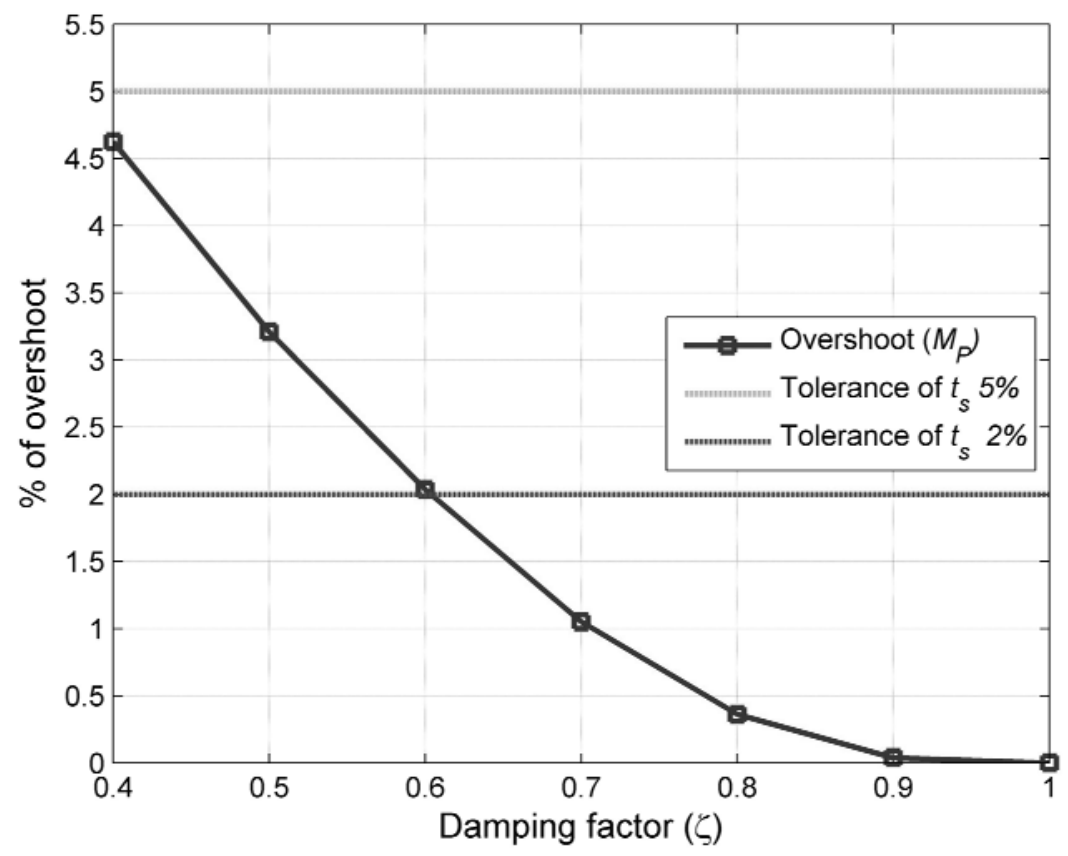

Figure 6. Overshoot of the second-order systems controlled with PID-SANNA. 


\subsection{Physical implementation of the PID-SANNA.}

The hardware used to build the intelligent sensor with the PID-SANNA was an 8 bits microcontroller, with $64 \mathrm{~Kb}$ of memory, analog to digital converter
(ADC) of 10 bits, digital to analog converter (DAC) of 8 bits, the clock of 20Mhz and communication under Control Area Network (CAN 2.0), this is shown in Figure 7.

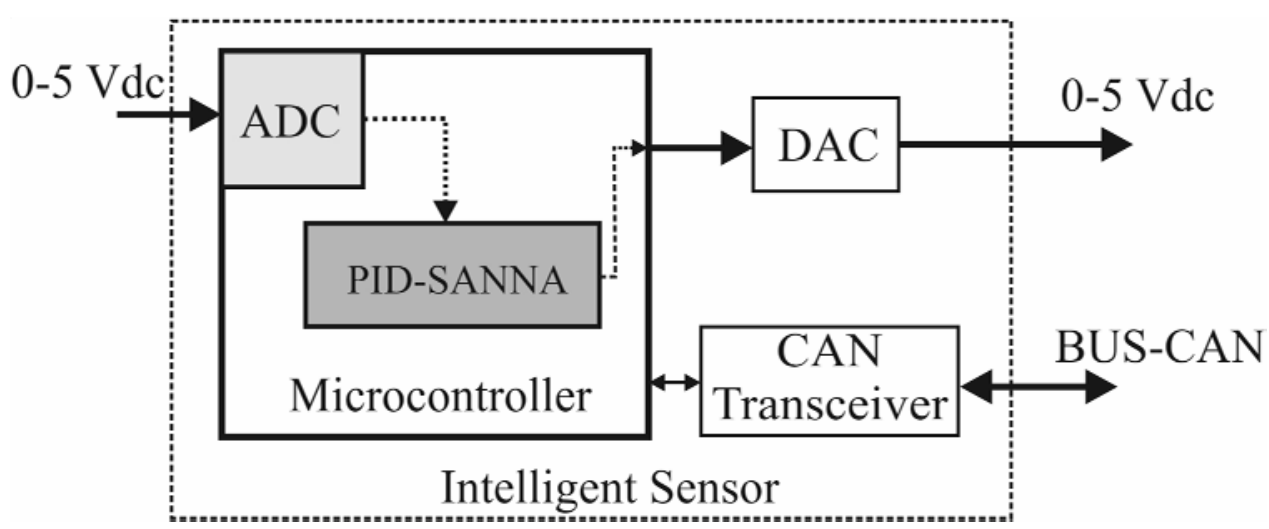

a)

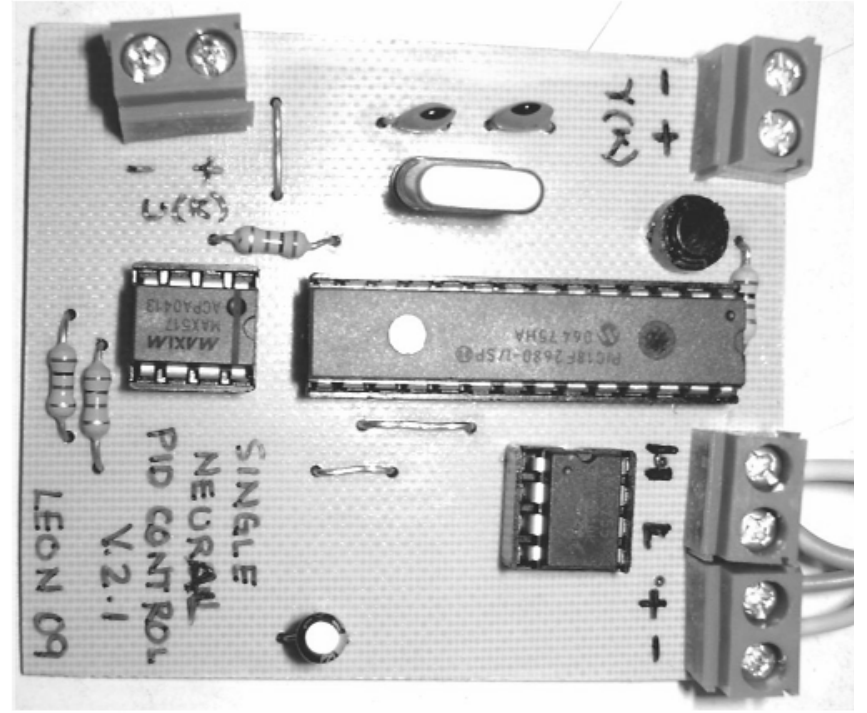

b)

Figure 7. Intelligent sensor with PID-SANNA. a) Architecture b) Physics prototype. 


\section{PID Based on a Single Artificial Neural Network Algorithm for Intelligent Sensors, J. Rivera-Mejía et al. / 262-282}

\subsection{Tests on real cases of PID-SANNA.}

For the practical evaluation of the PID-SANNA, three physical systems were used: a RC network, a motor of direct current (DC) and a oven, each experiment described as follows:

a) The RC network was used to evaluate the PID-SANNA performance. The dynamic performance of RC network is as firstorder system, changing the values of the resistor and the capacitor the delay time $\tau$ was changed in the range from $0.0047 \mathrm{~s}$ to $0.47 \mathrm{~s}$, as shown in Table 1 and the unit step response in open loop is shown in Figure 8.

\begin{tabular}{cccc}
\hline $\begin{array}{c}\text { System model } \\
\mathbf{G}_{\mathbf{P}}(\mathbf{s})\end{array}$ & Resistor $(\Omega)$ & Capacitor $(\mu \mathbf{F})$ & $\tau$ (s) \\
\hline$G_{P 1}(s)$ & 100 & 47 & 0.0047 \\
$G_{P 2}(s)$ & 1000 & 47 & 0.0470 \\
$G_{P 3}(s)$ & 3300 & 47 & 0.1551 \\
$G_{P 4}(s)$ & 4700 & 47 & 0.2209 \\
$G_{P 5}(s)$ & 10000 & 47 & 0.4700 \\
\hline
\end{tabular}

Table 1. RC network values.

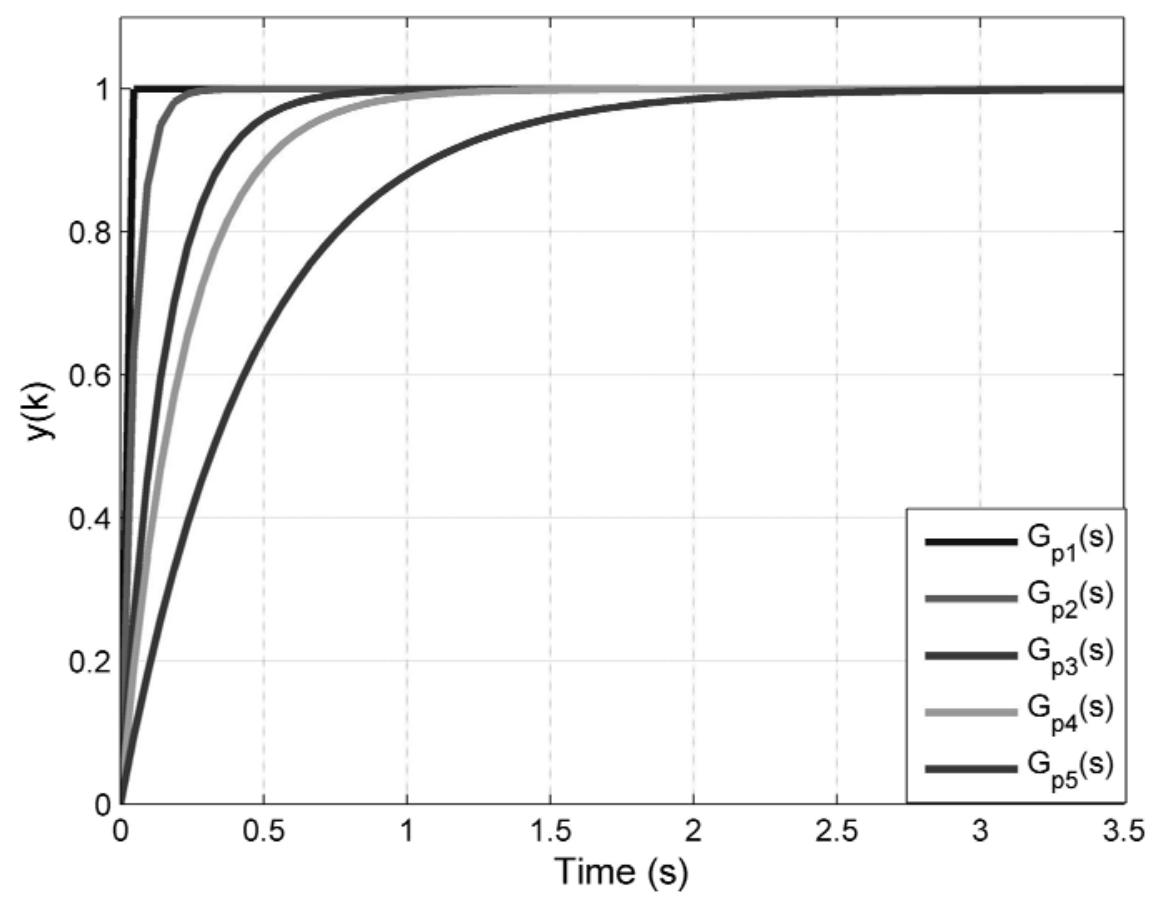

Figure 8. Step response in open loop of first-order systems:

(a) $=4.7 \mathrm{mS}$, (b) $=47 \mathrm{mS}$, (c) $=155.1 \mathrm{mS}$, (d) $=220.9 \mathrm{mS}$, (e) $=470 \mathrm{mS}$. 
b) The features of the DC motor used are: power supply requirements of $9 \mathrm{VDC}$ and Maximum speed of 1500 revolutions per minute (RPM). A simple circuit was added to the intelligent sensor to supply the right voltage and current to the motor and a tachometer was used to measure the speed motor. In order to evaluate the motor dynamic features, first a step of 5VDC as input signal was applied in the open loop to the motor; the response is shown in Figure 9. One speed of 1266 RPM was reached for the DC motor and the time constant was computed and it is of $\tau=98 \mathrm{~ms}$.

c) An electric oven of FELISA brand was used as a physical system to be controlled and to evaluate the performance of the PID-SANNA, Figure 10a. The oven has a electric resistor to produce heat and the power supply required is of $120 \mathrm{VAC}$ and 18.3 amperes. The oven produces a maximum temperature of $220{ }^{\circ} \mathrm{C}$. In order to make the oven power control a special full-wave AC/AC voltage controller was designed [45]. The output signal $u(k)$ of PID-SANNA, between 0 to 5 VDC, was applied to the power driver to make the commutation control of the two silicon controlled rectifiers (SCR's). The output signal of the power driver is as Figure $10 \mathrm{~b}$, the $\alpha$ value is directly proportional to the output signal $u(k)$ of the PID-SANNA. Note that $\alpha$ value controls the portion of VAC that will be supplied to the oven resistor. Now the portion of the VAC supplied to the oven resistor will be denoted as the percentage respect to the full wave that will be the $100 \%$ of VAC supplied.

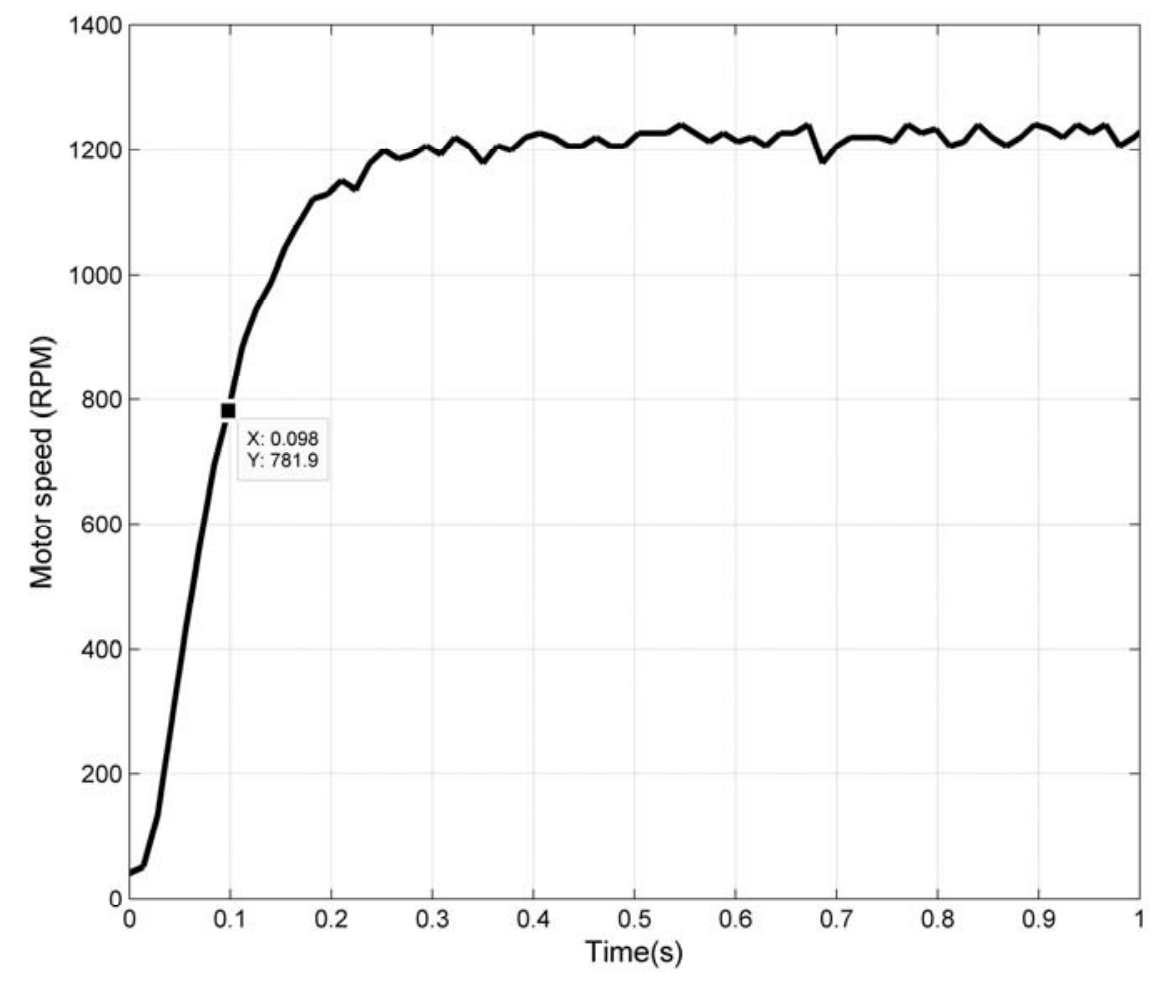

Figure 9. Motor response in open loop to a step as input signal. 


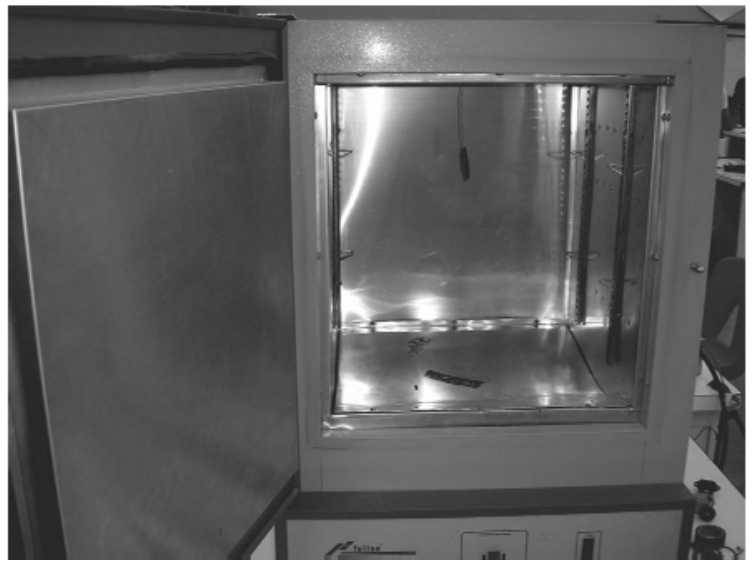

(a)

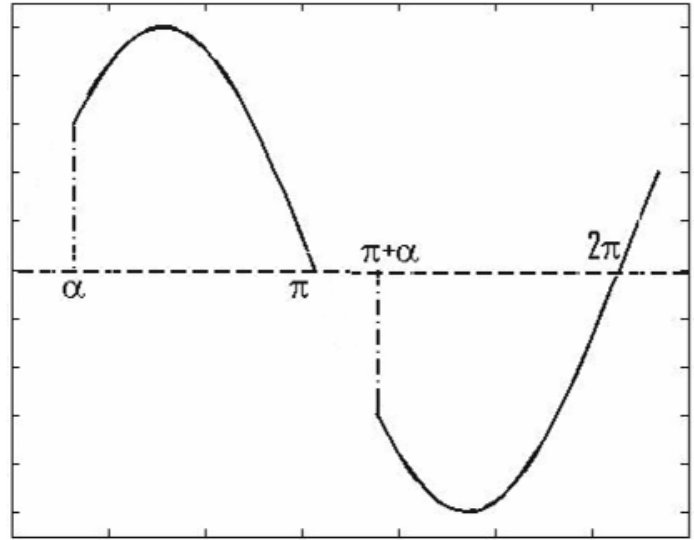

(b)

Figure 10. a) FELISA Oven. b) Output signal of the power driver.

The step response of the oven in conjunction with the full-wave AC/AC voltage controller changes if the percentage of the VAC applied to oven resistor changes. This means if the $\alpha$ value changes the oven performance changes. The oven step response in open loop when $95 \%$ of VAC and $37 \%$ VAC are applied to the oven resistor is shown in Figure 11. This system is a very interesting test for the PID-SANNA because the oven in conjunction with power driver represents a physical system with variable characteristics, difficult to be controlled with classical control methods. If the oven resistor is supplied with $95 \%$ of VAC the oven model is like a straight line, Figure $11 \mathrm{a}$, but if the oven resistor is supplied with $37 \%$ of VAC the oven model is like a first-order system, Figure 11b.

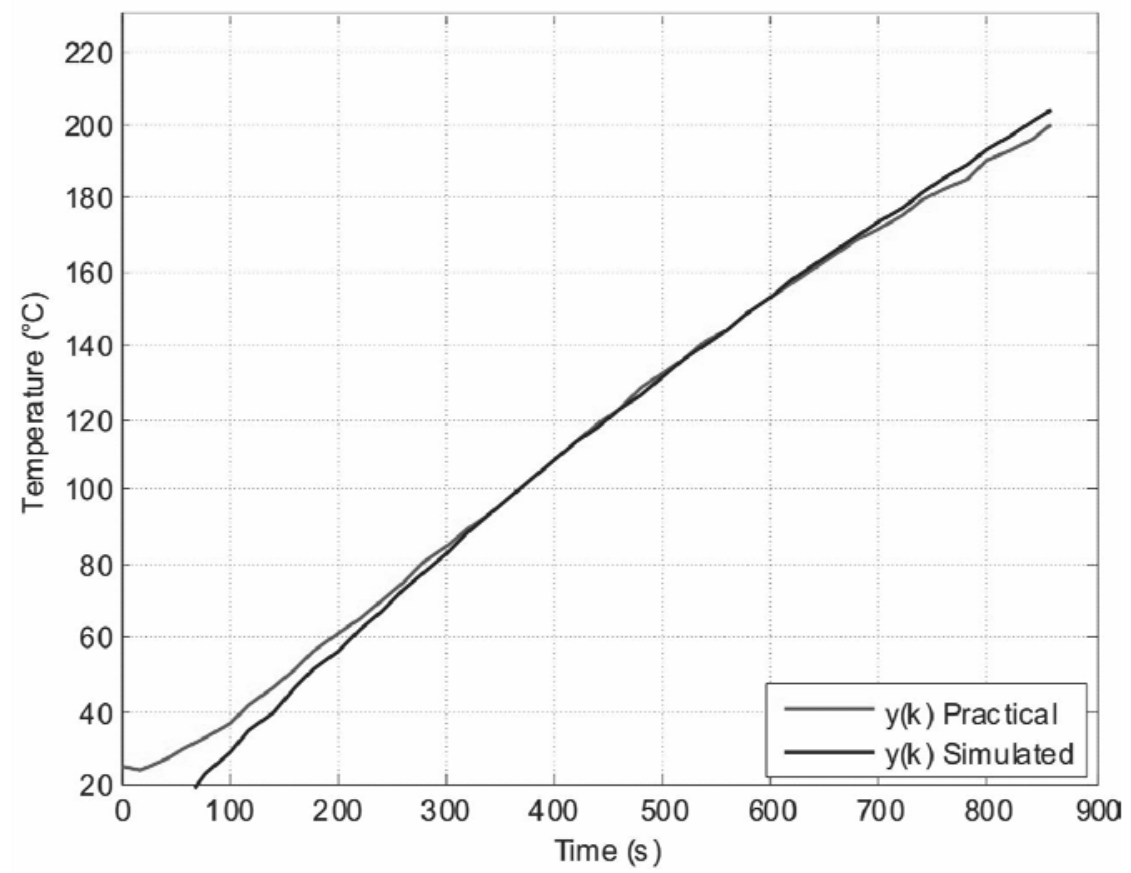

a) 


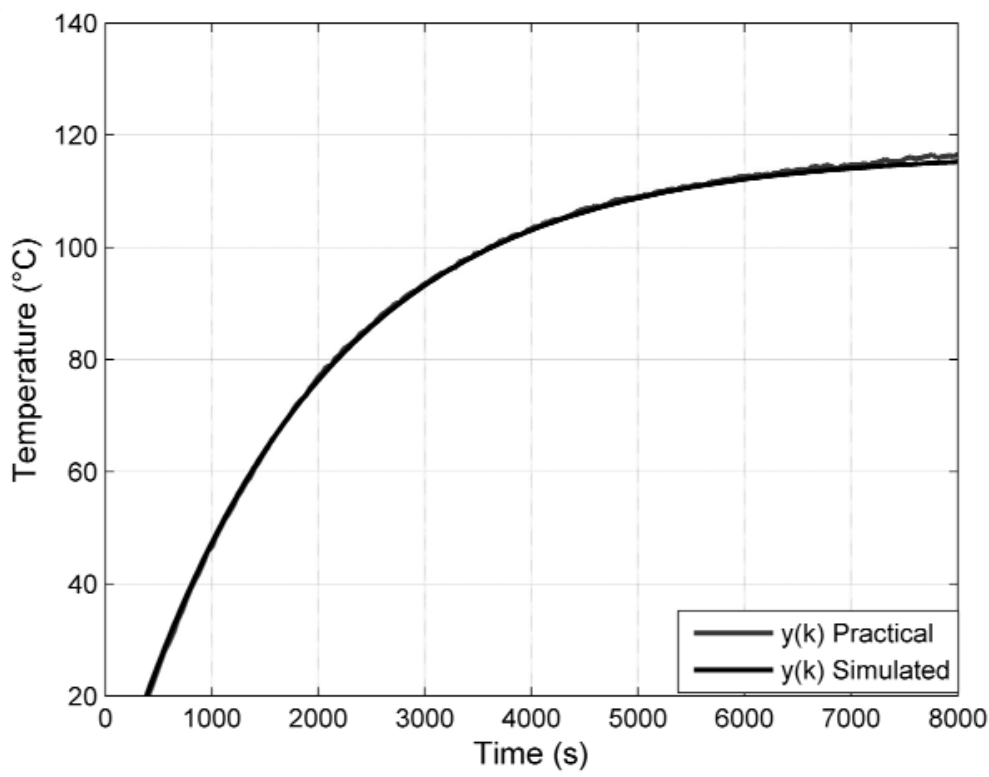

b)

Figure 11. Oven step response in open loop. a) Step of $95 \%$ of VAC. b) Step of $37 \%$ of VAC.

In the next section, the results obtained will be presented when each one of the physical systems were practically controlled by the PID-SANNA.

\section{RESULTS AND DISCUSSION}

All de physical systems described in Section 2.3 controlled with the PID-SANNA were tested. First the $\mathrm{RC}$ network, with values from Table 1, was tested and in Figure 12 the results of 3.5 VDC step input are shown. As can be observed, a similar response was obtained in simulation and practical test.

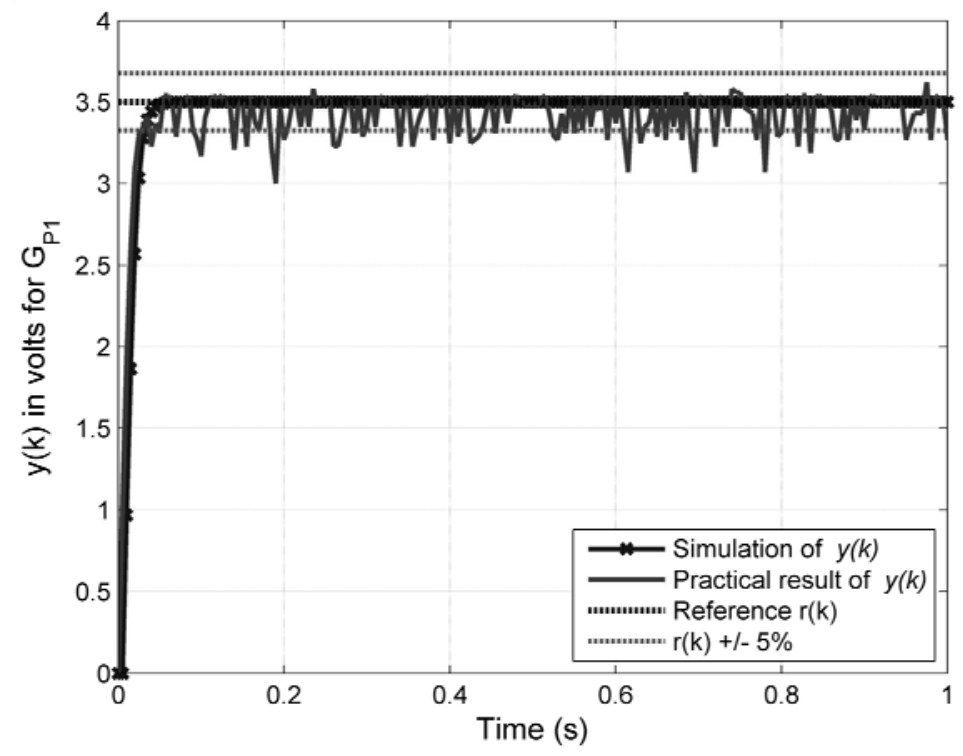

a) 


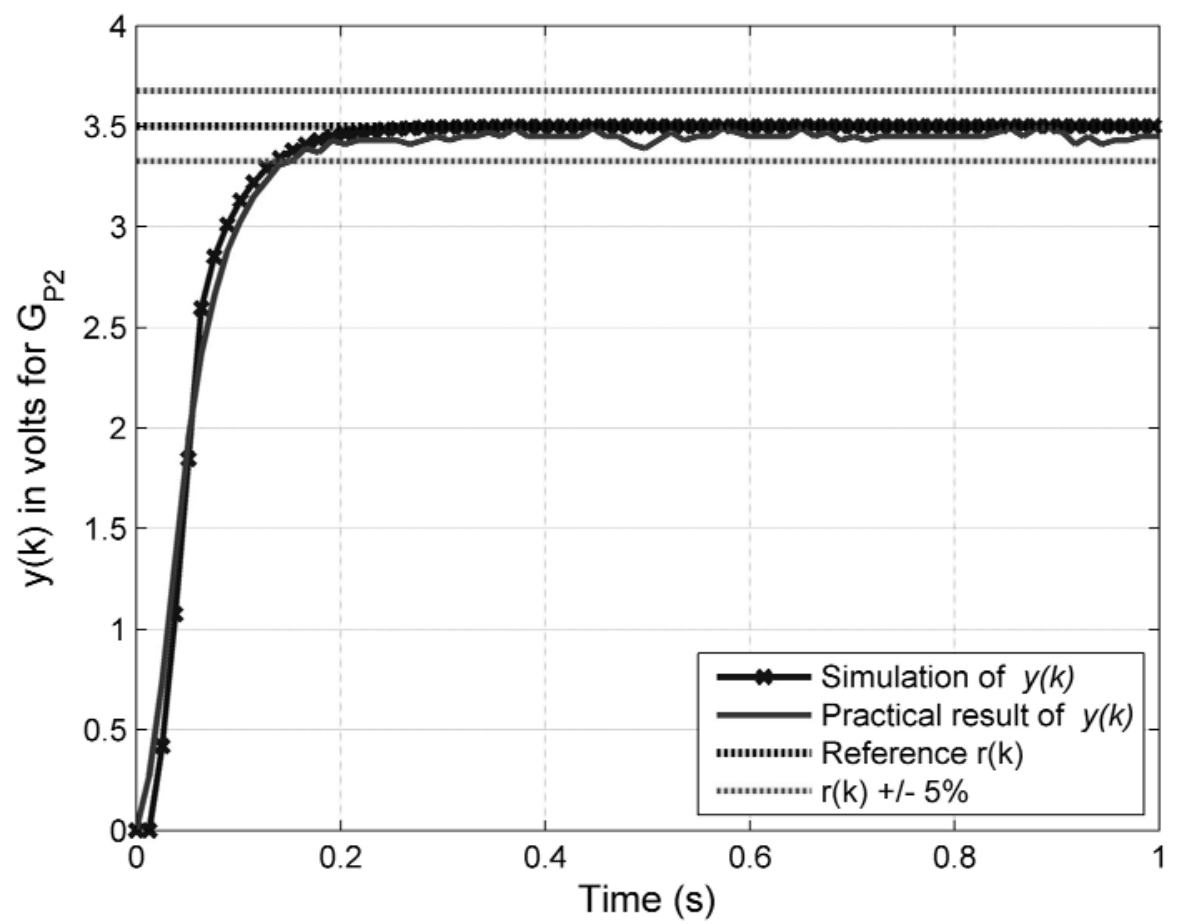

b)

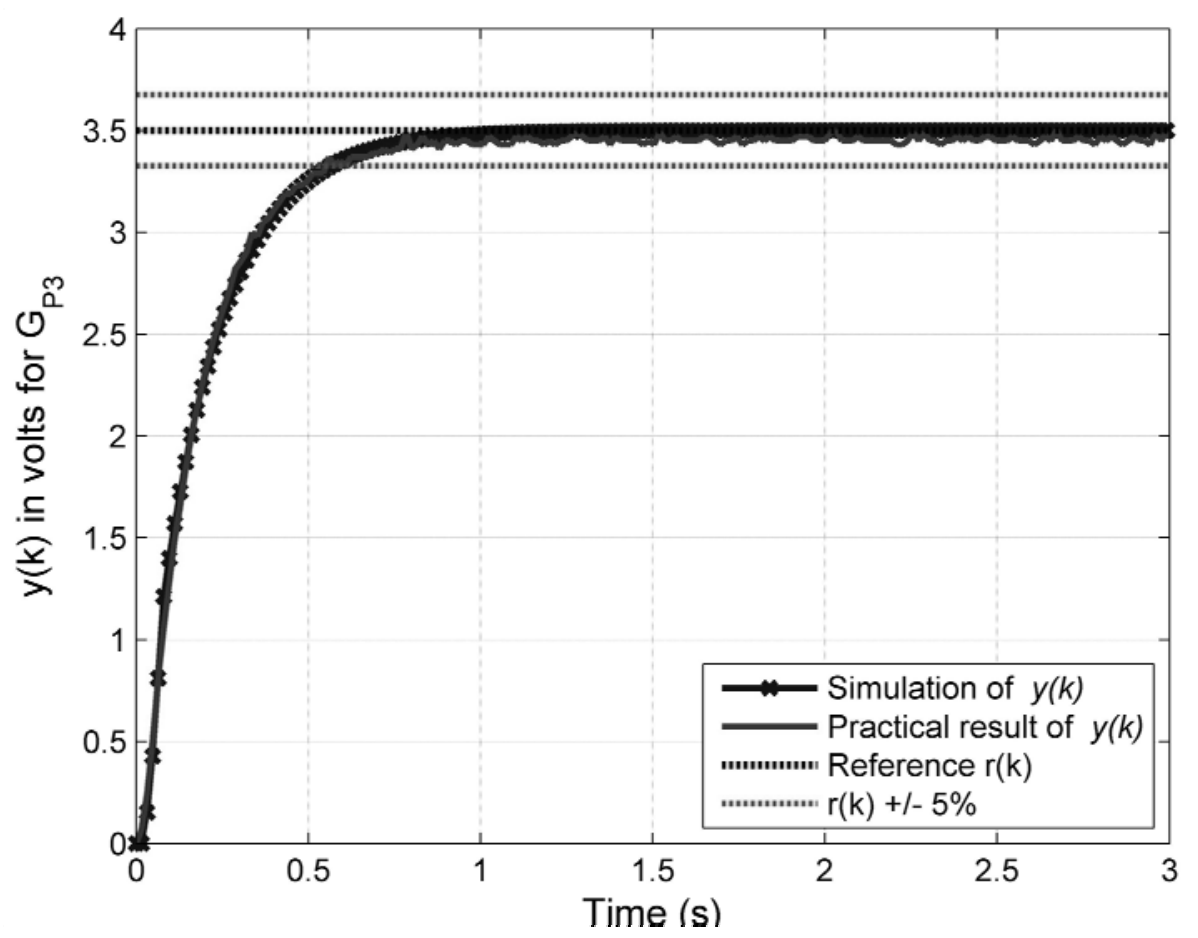

c) 


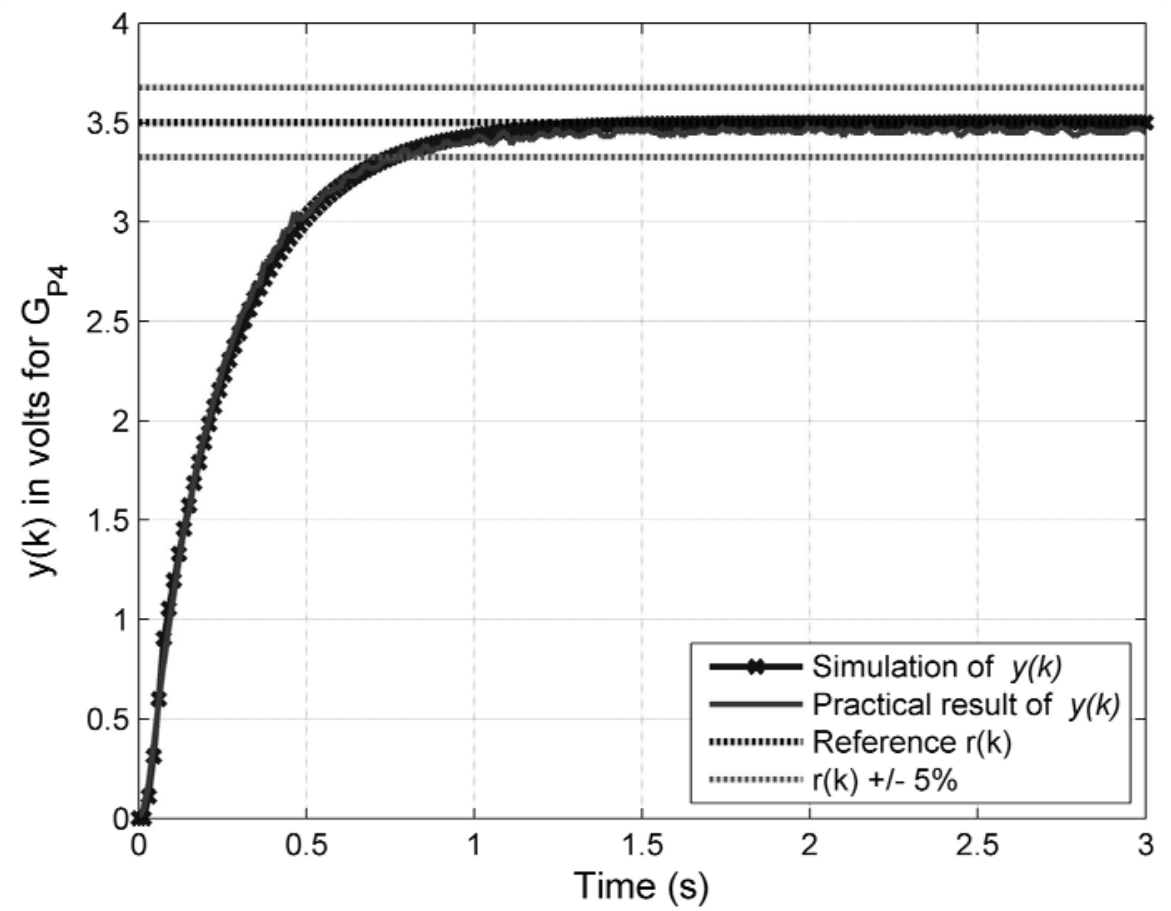

d)

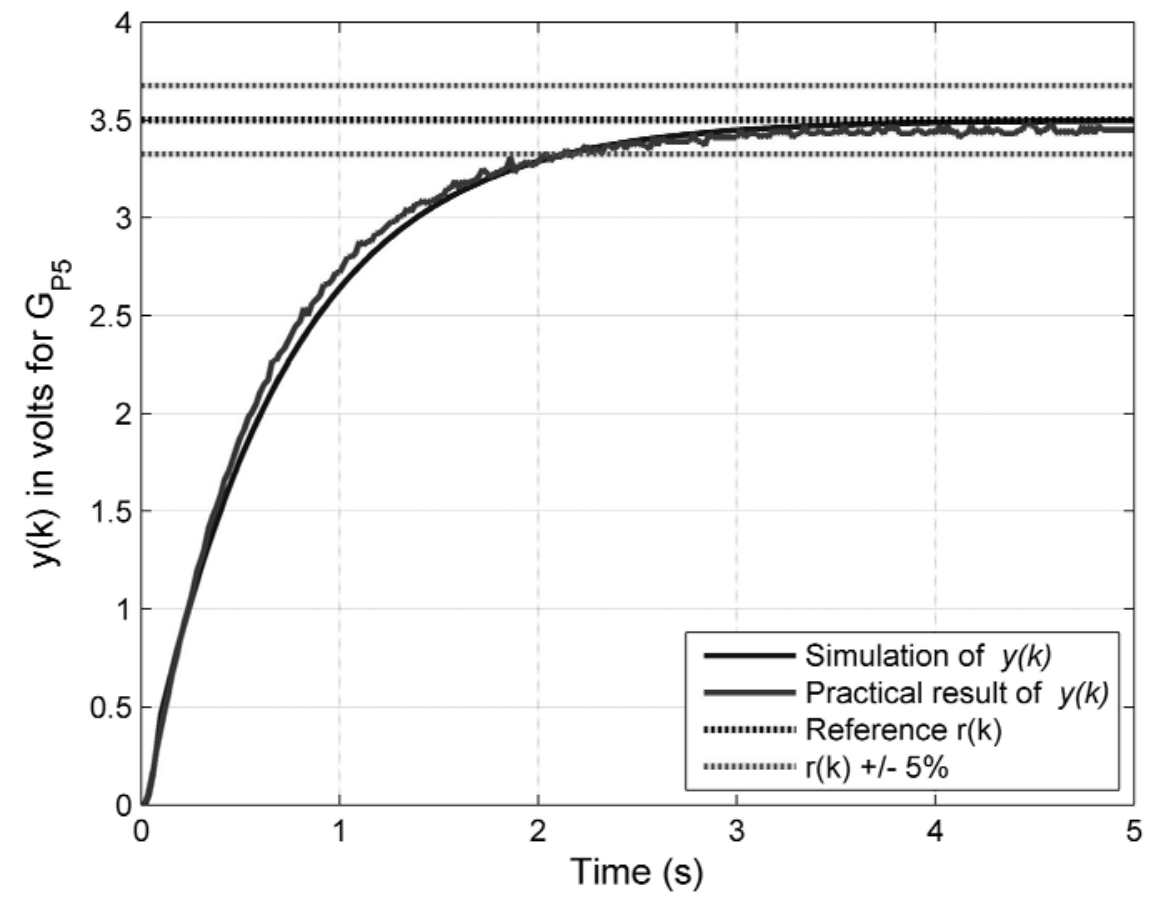

e)

Figure 12. Step response of first-order systems controlled with the PID-SANNA: (a) $\tau=4.7 \mathrm{mS}$, (b) $\tau=47 \mathrm{mS}$, (c) $\tau=155.1 \mathrm{mS}$, (d) $\tau=220.9 \mathrm{mS}$, (e) $\tau=470 \mathrm{mS}$. 


\section{PID Based on a Single Artificial Neural Network Algorithm for Intelligent Sensors, J. Rivera-Mejía et al. / 262-282}

Observe the results with the physical system of $G_{P 5}(s)$, where the practical response is not satisfactory, Figure 12a. The PID-SANNA expends $5 \mathrm{~ms}$ in its computation and the plant time constant is $4.7 \mathrm{~ms}$ and this is the reason why the PID-SANNA did not make the control well.
Second the DC motor introduced in Section 2.3b was controlled with the PID-SANNA and two tests were done. The response to step as input signal of magnitude of 633 RPM and 1266 RPM are shown in Figure 13. In both tests, first, the control response was simulated and after that, the practical test was done. If a limit of $5 \%$ is taken, the PID-SANNA works satisfactory.

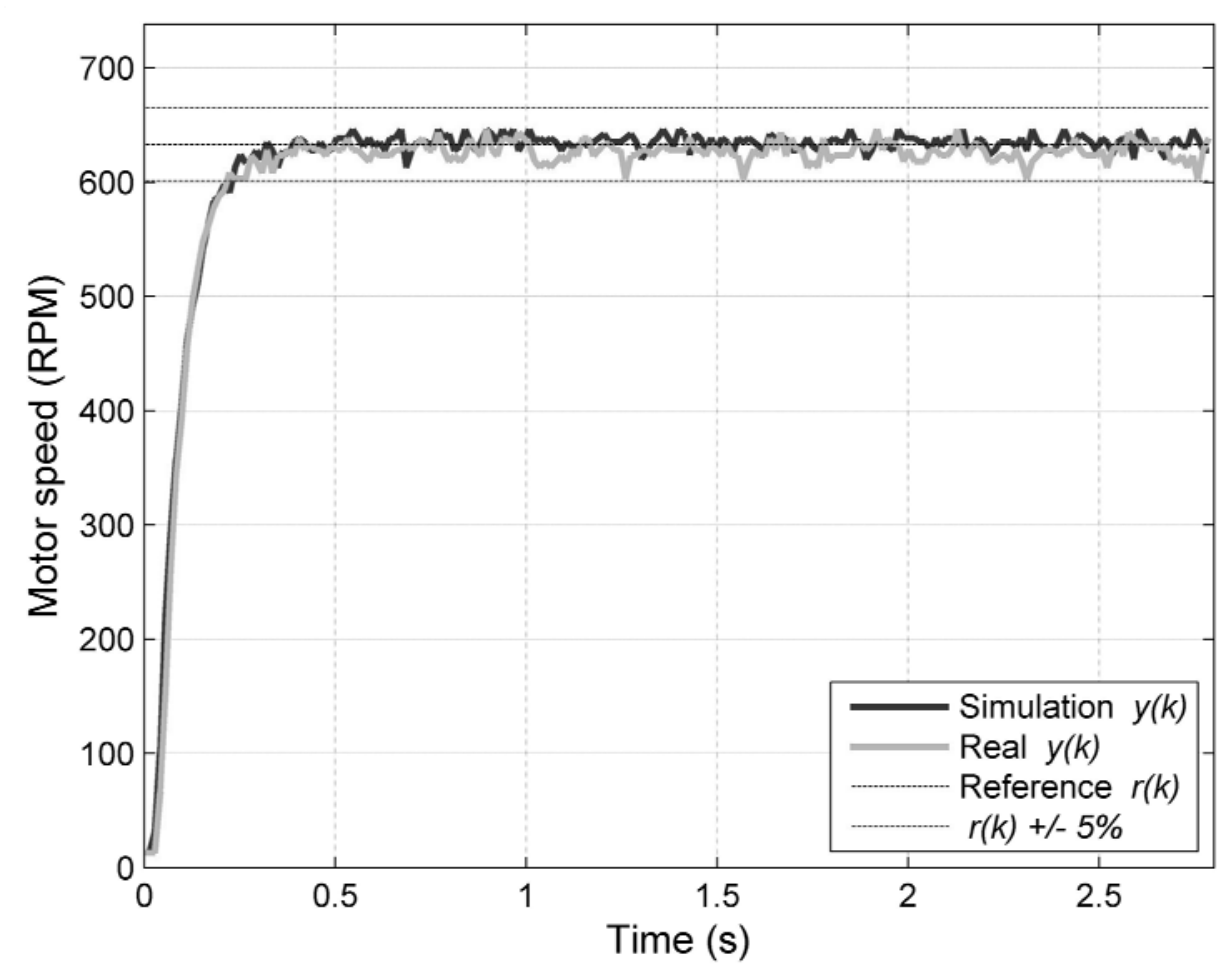

a) 


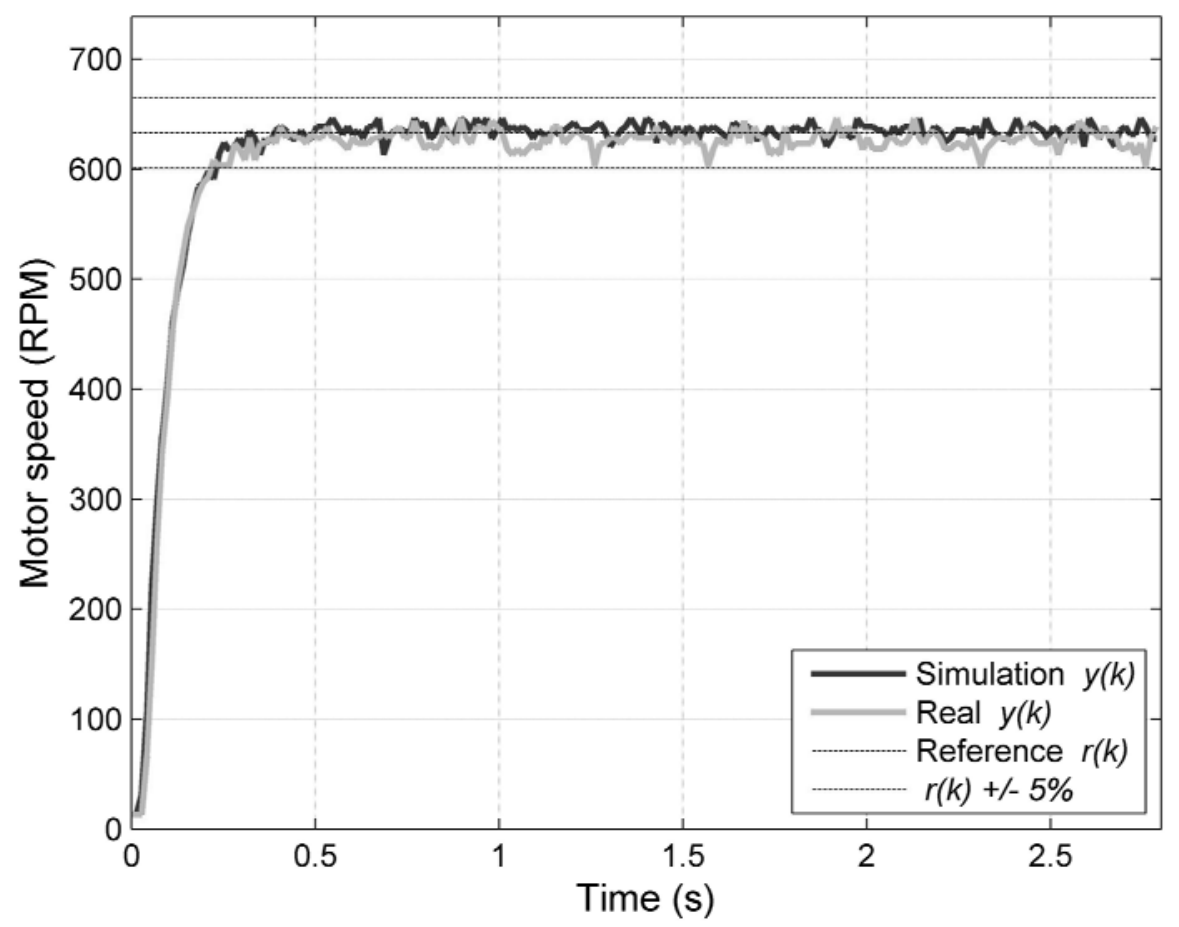

b)

Figure 13. Step response of the DC motor controlled with the PID-SANNA.

Third the oven described in Section 2.3c was controlled with the PID-SANNA and the $120{ }^{\circ} \mathrm{C}$ step response is shown in Figure 14. The timedomain specifications reached were the rise time $t_{r}=309 \mathrm{~s}$, time-to-peak overshoot $t_{p}=558 \mathrm{~s}$, the maximum overshoot $M_{p}=6.8^{\circ} \mathrm{C}$ and the settling time for tolerance of $5 \% t_{s}=667 \mathrm{~s}$.

From all the previous tests with the PID-SANNA is evident that it works well for those physical systems. However, the test could be not complete if the response of the PID-SANNA is not compared with a commercial controller. Then using a Honeywell controller, model UDC3000 with the traditional PID algorithm tuning under the ZiglerNichols method the oven was controlled and the results were compared with the previous results obtained with the PID-SANNA. The results of a step as input of $120^{\circ} \mathrm{C}$ of magnitude are showed in Figure 15 and the comparison of time-domain specifications results between the Honeywell and the PID-SANNA Controllers, applied to oven control, are shown in Table 2. Now, it can be observed easily, that with the PID-SANNA best results were reached. Another important issue to take into consideration is that the PID tuning of Honeywell control was done by a person with control knowledge, but with low practical training and expend almost one day working with the system, and even though, these were his better results.

In summary, the PID-SANNA control design was tested with different physical systems and it worked satisfactorily for first-order system with time constant up to $5 \mathrm{~ms}$ and it worked well for secondorder systems with damping factor up to 0.4. These restrictions are due to hardware that was used because around $4.7 \mathrm{~ms}$ is the consumed time for computing the PID-SANNA. Future improvement is the use of a digital signal processor (DSP) or a field programmable gate array (FPGA) instead of a microprocessor to build the intelligent sensor. 


\section{PID Based on a Single Artificial Neural Network Algorithm for Intelligent Sensors, J. Rivera-Mejía et al. / 262-282}

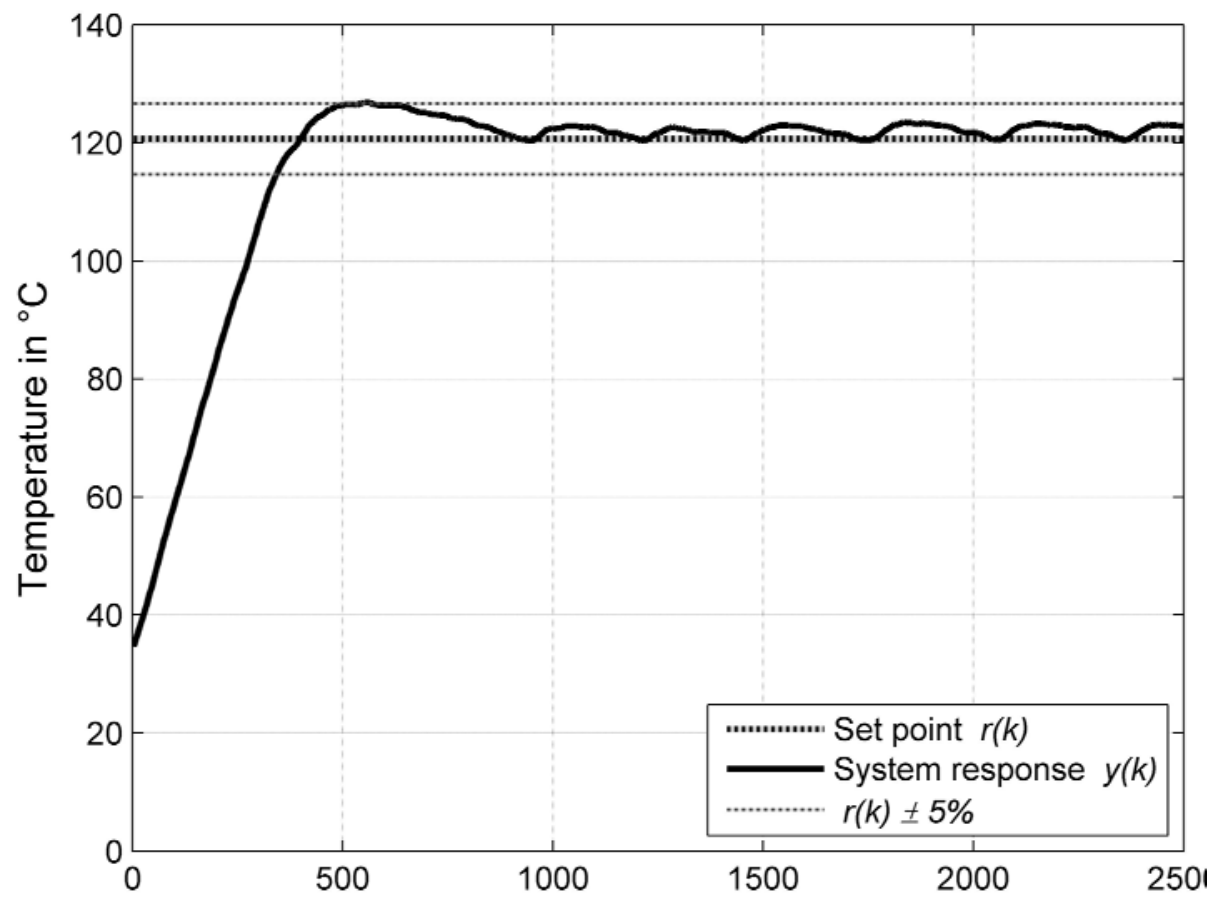

Figure 14. Step response of the oven controlled with the PID-SANNA.

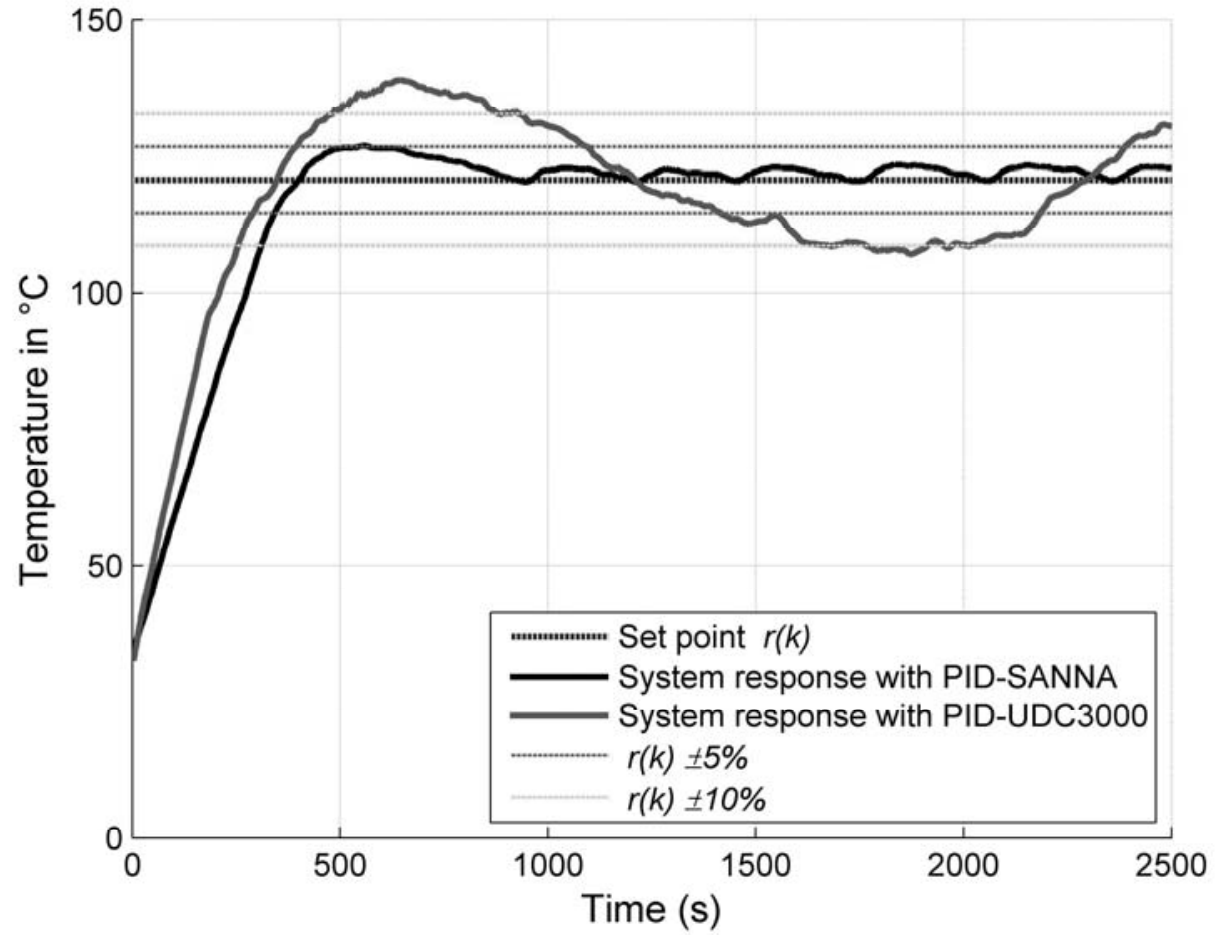

Figure 15. Step response of the oven controlled with the Honeywell controller and the PID-SANNA. 


\begin{tabular}{ccc}
\hline Features & PID-SANNA & $\begin{array}{c}\text { Honeywell } \\
\text { Controller (UDC3000) }\end{array}$ \\
\hline Delay time $\left(t_{d}\right)$ & $105 \mathrm{~s}$ & $75 \mathrm{~s}$ \\
Rise time $\left(t_{r}\right)$ & $309 \mathrm{~s}$ & $258 \mathrm{~s}$ \\
Time-to-pick overshoot $\left(t_{p}\right)$ & $558 \mathrm{~s}$ & $648 \mathrm{~s}$ \\
Maximum overshoot $\left(M_{p}\right)$ & $6.8{ }^{\circ} \mathrm{C}$ & $19{ }^{\circ} \mathrm{C}$ \\
Settling time $\left(t_{s}\right)$ & $667 \mathrm{~s}$ & $>2016 \mathrm{~s}$ \\
\hline
\end{tabular}

Table 2. Comparison of the time-domain specifications of the Honeywell and the PID-SANNA Controllers.

Now, easily, a network of intelligent sensors with control capability can be built. An example is shown in Figure 16, using the CAN communication is possible to get a local network of intelligent sensors and this network could be connected to one central computer, this network could be connected to global network. This example is one of several topologies that can be built now and, from remote location, the set point for each intelligent sensor can be placed.

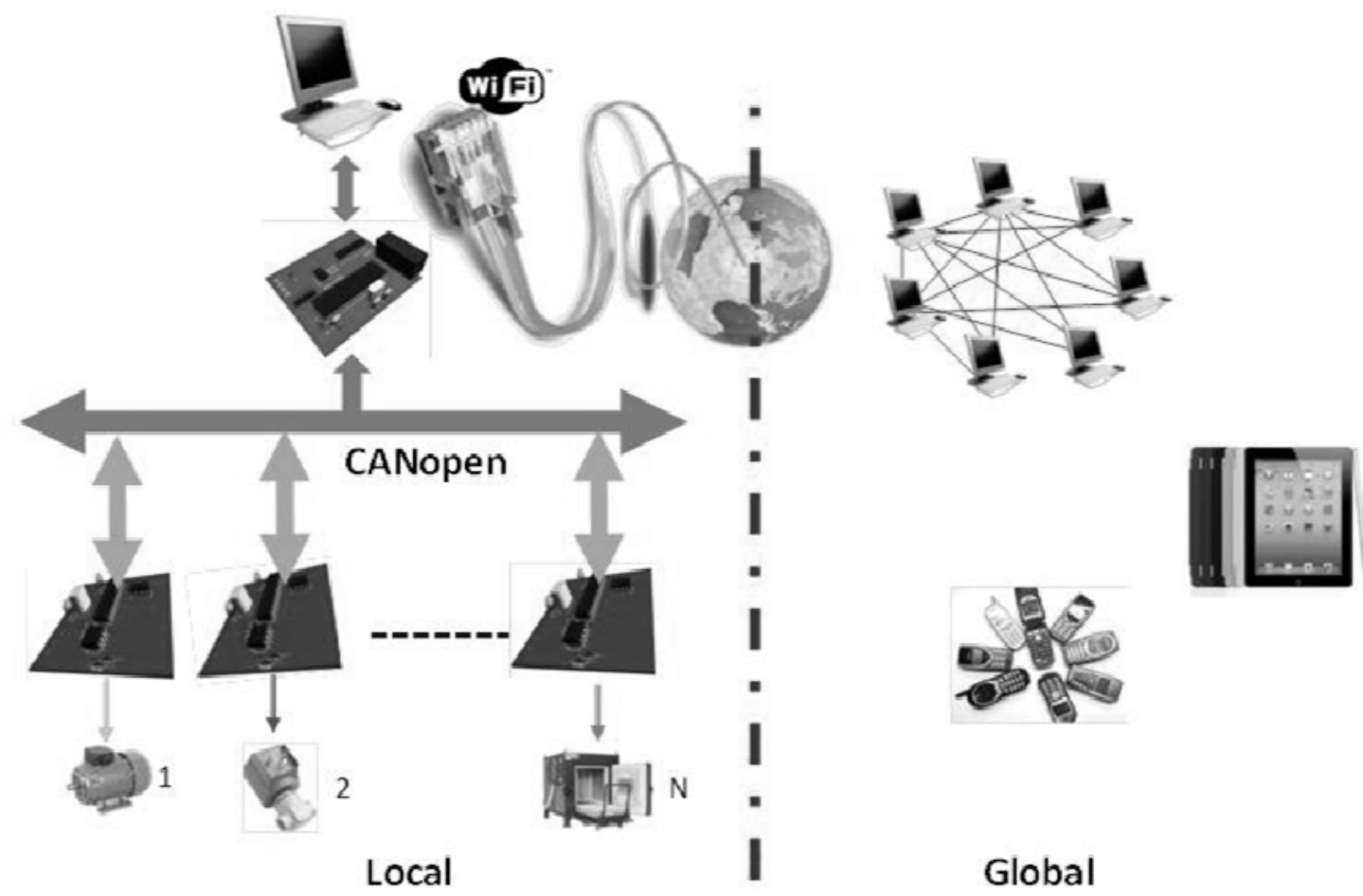

Figure 16. Example of a possible application using intelligent sensors with PID-SANNA. 


\section{Conclusions}

In this paper the design of a PID control based on a single artificial neural network was presented. The design was focused on improving the performance and establishing the initial parameters to assure the control of different physical systems and not only to solve a particular problem. In order to increase the confidence in the intelligent control, the design was tested using simulation of physical systems of first and second order and the step response was used to assess performance, Figures 3 and 5. The PIDSANNA was implemented on an intelligent sensor that uses a small microcontroller as shown in Figure 7. After that, to evaluate the PID-SANNA three real systems were used; a RC network, a DC motor and an oven, described in Section 2.3. With the oven, it was proved that the PID-SANNA has the capability to maintain under control a physical system with changing characteristics as shown in Figure 11 to Figure 14. Also, under time-domain specifications the PID-SANNA performance was compared with the performance of a commercial control as shown in Figure 15 and Table 2.

With the use of the PID-SANNA the set up time to control an unknown physical system is reduced to a simple test, the step response. With this, the user would define if the PID-SANNA will control.

In summary, an intelligent sensor with control capability was designed, to be used in a simple way for any user with minimal control knowledge. The intelligent sensor can control a wide variety of physical systems like, first-order system with time constant up of $5 \mathrm{~ms}$ and second-order systems with damping factor up of 0.4. These characteristics are limited by hardware used, but if building intelligent sensor in a DSP or FPGA, the features will be substantially increased. Also, an example of distributed control using the intelligent sensors is presented in Figure 16.

\section{Acknowledgments}

This work was financially supported by the Instituto Tecnológico de Chihuahua, FOMIX-Chihuahua (Project No. CHIH-2009-C01-116741) and PROMEP (Project No. ITCH-EXB-001). Thanks are also to the students at the Instrumentation and Control Laboratory (year 2010-2011).

\section{References}

[1]. Frank R., In Understanding Smart Sensors; Artech House: Norwood, Massachusetts, 2000, pp. 3.

[2]. Robert M., Riviere J. M., Noizette J. L.; Hermann, F., Smart sensors in flexible manufacturing systems, Sensors and Actuators: A Physical, Vol. 37-38, No. C, June, 1993, pp. 239-246.

[3]. Meijer, G. C. M., Concepts and focus point for intelligent sensor systems Sensors and Actuators: A Physical. Vol 41, No. 1-3, April, 1994, pp. 183-191.

[4]. Tian, G. Y., Zhao Z. X., Baines, R. W., Fieldbusbased intelligent sensor, Mechatronics, Vol. 10, No. 8, December, 2000, pp 835-849.

[5]. Mekid S., Further Structural Intelligence for Sensors Cluster Technology in Manufacturing. Sensors, No. 6, June, 2006, pp. 557-577.

[6]. Rivera J., Herrera G., Chacón M., Acosta P., Carrillo M., Improved Progressive Polynomial Algorithm for SelfAdjustment and Optimal Response in Intelligent Sensors, Sensors, No. 8, November, 2008, pp. 7410-7427.

[7]. Hernandez W., Robust Multivariable Estimation of the Relevant Information Coming from a Wheel Speed Sensor and an Accelerometer Embedded in a Car under Performance Test. Sensors, No. 5, November, 2005, pp. 488-508.

[8]. Hernandez. W., Improving the Response of a Load Cell by Using Optimal Filtering. Sensors, No. 6, July, 2006, pp. 697-711.

[9]. Miskowiccz, M., Asymptotic Effectiveness of the Event-Based Sampling according to the Integral Criterion. Sensors, No. 7, January 2007, pp. 16-37.

[10]. Hernandez, W., A Survey on Optimal Signal Processing Techniques Applied to Improve the Performance of Mechanical Sensors in Automotive Applications. Sensors, No. 7, January 2007, pp. 84-102.

[11]. Hernandez W., De Vicente J., Sergiyenko O.Y., Fernández E., Improving the Response of Accelerometers for Automotive Applications by Using LMS Adaptive Filters. Sensors, No. 10, December, 2010, pp. 313-329.

[12]. Hernandez W., De Vicente J., Sergiyenko O.Y., Fernández E., Improving the Response of Accelerometers for Automotive Applications by Using 
LMS Adaptive Filters: Part II. Sensors No. 10, January, 2010, pp. 952-962.

[13]. Heong K., Chong G., PID Control System Analysis, Design, and Technology. IEEE Transactions on Control Systems Technology. Vol. 13, No.4, July, 2005, pp. 559-576.

[14]. Palma L.S., Oliveira A., Costa A. S., Andrade A. Q., Almeida C. V. R., Zurita M. E. P. V., Freire R. C. S. Implementation of a I2-Controlled Constant Temperature Environment Temperature Meter, Sensors No. 3, October, 2003, pp. 498-503.

[15]. Sanchéz J., Guarnes M. A., Dormido S. On the Aplication of Diferent Event-Based Sampling Strategies to the Control of a Simple Industrial Process, Sensor, No. 9, August 2009, pp. 6795-6818.

[16]. Treeprapin K., Kanzaki A., Hara T., Nishio S. An Effective Mobile Sensor Control Method for Sparse Sensor Networks. Sensors, No. 9, January 2009, pp. 327-354.

[17]. Xia F., Ma L., Peng Ch., Sun Y., Dong J. CrossLayer Adaptive Scheduling of Wireless Control Systems. Sensors, No. 8, July, 2008, pp. 4265-4281.

[18]. Gutiérrez A., Jiménez L. J., Magdalena L. A Distributed Sensor Network for the Control of a Bioclimatic House in Spain. Sensors, No. 9, October 2009, pp. 8197-8214.

[19]. Wu M., Cao W., He Ch. Y., She J.H. Integrated Intelligent of Gas Mixing and Pressurization Process. IEEE Transactions on Control Systems Technology. Vol. 17, No.1, January, 2009, pp. 68-77.

[20]. Xi F., Zhao W., Sun Y., Tian Y. Ch., Fuzzy Logic Control Based QoS Management in Wireless Sensor/Actuator Network. Sensors, No. 7, December, 2007, pp 3179-3191.

[21]. Jung S., Kim S. S., Control Experiment of WheelDriven Mobile Inverted Pendulum Using Neural Network. IEEE Transactions on Control Systems Technology. Vol.16, No.2, March, 2008, pp 297-303.

[22]. Wang J. J., Zhang C. F., Jing Y.Y., Self-Adaptive RBF Neural Network PID Control in Exhaust Temperature of Micro Gas Turbine. Proceeding of 7TH International Conference on Machine Learning and Cybernetics, 2008, pp. 2131-2135, Kunming, China, July.

[23]. Han W. Y., Han J. W., Lee, Development of Selftuning PID Controller base on Neural Network for Nonlinear Systems. Proceedings of the 7th Mediterranean on Control and Automation, 1999, pp 979988, Haifa Israel, June.
[24]. Chang W. D., Hwang R.Ch., Hsieh J.G., A multivariable on-line adaptive PID controller using autotuning neurons. Engineering Applications of Artificial Intelligence, Vol. 16, No.1, February, 2003, pp. 57-63.

[25]. Mohamadian M., Nowicki E.P., Salmon J.C., A neural Network Controller for Indirect Field Orientation Control, Conference Record of the 1995 IEEE Industrial Applications Conference Thirtieth IAS Annual Meeting. 1995, pp. 1770-1774, Orlando, United States of America, October.

[26]. Lizarraga I., Etxebarria V., Real-time adaptive neural control of class of nonlinear systems Engineering Applications of Artificial Intelligence, Vol. 12, No.1, February, 1999, pp. 3-19.

[27]. Zerkaoui S., Druaux F., Leclercq E. Lefebvre D., Stable adaptive control with neural networks for square MIMO no-linear systems. Engineering Applications of Artificial Intelligence, Vol. 22, No. 4-5, June, 2009, pp. 702-717.

[28]. Peng H., Yang Z. J., Gui W., Wu M., Shioya H., Nakano K., Nonlinear System Modeling and robust predictive control based on RBF-ARX model. Engineering Applications of Artificial Intelligence, Vol. 20, No. 1, February, 2007, pp 1-9.

[29]. Jung S., Kim S. S., Hardware Implementation or Real-Time Neural Network Controller With a DSP and FPGA for Nonlinear Systems. IEEE Transactions on Industrial Electronics. Vol. 54, No.1, February, 2007, pp. 265-271.

[30]. Ning W., Shuqing W., Jianming Z. A Model Reference Intelligent Controller Using a Single Neuron. Proceeding of International Conference On Info-tech. and Info-net 2001, ICII 2001, 2001, pp. 170-173, Beijing, China, October.

[31]. Sheng Q., Xianyi Z., Changhong W., Gao X. Z., Zilong L. Design and Implementation of An Adaptive PID Controller Using Single Neuron Learning Algorithm. Proceeding of the 4th World On Intelligent Control and Automation, 2002, pp. 2279-2283. Shanghai, China, June.

[32]. Qin Z. M., Zhang L. Y., Gu J. J., Wang L., Single_Neuron PSD Adaptive Control Based on Smith Predictor for the Main Stream Temperature. Proceeding of the Third International Conference on Machine Learning and Cybernetics. 2004, pp. 1088-1092, Changhai, China, August.

[33]. Sun D., Meng J., A Single Neuron PID Controller Based PMSM DTC Drive System Fed by Fault Tolerant 4-Switch 3-Phase Inverter, 1st IEEE Conference on 
Industrial Electronics and Applications, 2006, pp. 1-5, Singapore, Singapore, May.

[34]. Shi T., Xia Ch., Wang M., Zhang Q., Single Neural PID Control for Sensorless Switched Reluctance Motor Based on RBF Neural Network. Proceeding of the 6th World Congress on Intelligent Control and Automation. 2006, pp. 8069-8073, Dalian, China, June.

[35]. Guang Z., Min Q. K., Yan M. S., Qi G. F., Single Neutral Element Self-Adaptive PID Controller Used In SVC. CES / IEEE 5th International Power Electronics and Motion Control Conference, IPEMC 2006, 2006, pp. 1-5, Shanghai, China, August.

[36]. Zhang M. G., Li W. H., Single Neuron PID Model Reference Adaptive Control Based on RBF Neural Network. Proceeding of the Fifth International Conference On Machine Learning and Cybernetics. 2006, pp. 3021-3025, Dalian, China, August.

[37]. Sun J., Chan S., Ko K. T., Chen G.; Zukerman M. Neuron PID: A Robust AQM Scheme. Proceeding of Australian Telecommunication Network and Applications Conference ATNAC 2006, 2006, pp. 259-262, Melbourne, Australia, December.

[38]. Xia Ch., Li Z., Song P., Wang Y., A Current Control Algorithm based On Variable Current Threshold for FourSwitch Three-phase BLDCM using Intelligent Controller. IEEE International Conference On Industrial Technology, ICIT-2008, pp. 1-5, Chengdu, China April.

[39]. Yang Z., Zhao J., Zheng T. Q., High Performance Vector Control of Linear Induction Motors Using Single Neuron controller. Fourth International Conference on Natural Computation, ICNC'08, 2008, pp. 534-537, Jinan, China, October.

[40]. Zhao Q., Yang Y., Improved Single Neuron PID Control for Heavy-Duty Vehicle Magnetorheological Seat Suspension, IEEE Vehicle Power and Propulsion Conference, VPPC-2008, pp. 1-3, Harbin, China, September.

[41]. Liu X., Single Neuron Self-tuning PID Control for Welding Molten Pool Depth. Proceeding of the 7th World Congress On Intelligent Control and Automation. 2008, pp. 7922-7925, Chongqing, China, June.

[42]. An S., Shao L., Diesel Engine Common Rail Pressure Control Based on Neuron Adaptive PID. IEEE International Conference on Cybernetics and Intelligent Systems. 2008, pp. 714-717, Chengdu, China, September.
[43]. Wang X., Xu B., Ding L., Simulation Study on A Single Neuron PID Control System of DC/DC Converters. Work Shop On Power Electronics and Intelligent Transportation System, PEITS'2008. Pp. 127-130, Guangzhou, China, August.

[44]. Ogata K. Discrete-Time Control Systems, Prentice Hall Inc, 1996.

[45]. Rashid H. M., Power Electronics Handbook; Academic Press: San Diego, California, 2001, pp. 169. 